\title{
Keratoepithelin reverts the suppression of tissue factor pathway inhibitor 2 by MYCN in human neuroblastoma: A mechanism to inhibit invasion
}

\author{
JUERGEN BECKER ${ }^{1,4}$, SONJA VOLLAND ${ }^{1,4}$, IEVGENIIA NOSKOVA ${ }^{1}$, \\ ALEXANDER SCHRAMM $^{2}$, LOTHAR L. SCHWEIGERER ${ }^{3}$ and JOERG WILTING ${ }^{4}$
}

\begin{abstract}
${ }^{1}$ Abteilung Hämatologie und Onkologie, Zentrum für Kinderheilkunde und Jugendmedizin, Universitätsmedizin Göttingen, D-37075 Göttingen; ${ }^{2}$ Abteilung Hämatologie, Onkologie und Endokrinologie, Universitätsklinikum Essen-Duisburg, D-45122 Essen; ${ }^{3}$ Helios Klinikum Berlin-Buch, Klinik für Kinder und Jugendmedizin, D-13125 Berlin; ${ }^{4}$ Abteilung Anatomie und Zellbiologie, Zentrum Anatomie, Universitätsmedizin Göttingen, D-37075 Göttingen, Germany
\end{abstract}

Received July 27,2007; Accepted September 25, 2007

\begin{abstract}
Neuroblastoma is the most frequent solid malignancy of children. The most reliable prognostic factor in neuroblastoma is the amplification status of the MYCN oncogene, but exceptions from this rule have been observed. Recently we have demonstrated that keratoepithelin (BIGH3, TGFBI) expression significantly reduces proliferation and invasion of neuroblastomas in vitro and in vivo. In these experiments, we also observed that tissue factor pathway inhibitor 2 (TFPI2, PP5, MSPI), a potent inhibitor of matrix-metalloproteinases, is most prominently up-regulated. As $M Y C N$-amplified neuroblastomas are highly invasive, we sought to determine the interaction between MYCN, keratoepithelin and TFPI2. In this study we provide initial evidence that i) keratoepithelin expression in neuroblastoma inversely correlates with $M Y C N$ expression; ii) TFPI2 expression in neuroblastoma also correlates inversely with $M Y C N$ expression but positively with keratoepithelin expression and iii) keratoepithelin induces elevated TFPI 2 transcript levels in neuroblastoma cells without alterations of $M Y C N$ expression.
\end{abstract}

\section{Introduction}

In children, neuroblastoma is the most frequent solid extracranial tumour. It is derived from neural crest-born neuroblasts of the sympathetic nervous system; only $5 \%$ being of parasympathetic origin. Despite advances in therapeutic regimens, approximately $40 \%$ of all patients and $70 \%$ of patients with

Correspondence to: Dr Juergen Becker, Zentrum Anatomie, Abteilung Anatomie und Zellbiologie, Universitätsmedizin Göttingen, Kreuzbergring 36, D-37075 Göttingen, Germany

E-mail: juergen.becker@med.uni-goettingen.de

Key words: BIGH3, tissue factor pathway inhibitor 2, MYCN, matrix-metalloproteinases, tumour progression, neuroblastoma advanced tumour stages die because of the disease. Today, we know a few genetic and molecular alterations that are considered to correlate with the outcome of neuroblastoma patients. Amplification of the $M Y C N$ oncogene, expression of the neurotrophin receptor TrkB, deletions of chromosome 1 and decreased expression of TrkA or activin-A are indicators of a poor prognosis, whereas high expression of $\operatorname{TrkA}$ or activin-A improves the prognosis for the patients $(1,2)$. Today, the most significant marker is the amplification status of the $M Y C N$ oncogene, which is clinically used for patient stratification. $M Y C N$-amplified neuroblastomas are the prototype of highly aggressive, rapidly growing tumors that demand immediate medical intervention (3).

Aggressive tumours all share the ability to grow rapidly, to induce and recruit blood vessels from the surrounding tissue, and to invade and destroy neighbouring tissues by proteolytic mechanisms. Invasion of blood and lymphatic vessels is a prerequisite for distant metastatic spread of tumour cells. Tumours invade adjacent tissues by degradation of the extra-cellular matrix (ECM), whose major constituents are collagen, elastin, glycosaminoglycans and proteoglycans. A multitude of degrading enzymes can participate in this process, nevertheless, matrix-metalloproteinases (MMPs), of which more than 25 are known so far, are the major players (4). As remodelling of the ECM is a normal event wherever cells, tissues and organs are developing or migrating, this process is tightly controlled in embryonic and healthy tissues. In the intercellular space, secreted MMPs are usually activated from inactive proenzymes by proteinases and degrade collagen, elastin and other proteins of the ECM. Furthermore, their activity is controlled by TIMPs (tissue inhibitors of metalloproteinases), which are released from the ECM during degradation. TFPI2 (tissue factor pathway inhibitor 2), also known as placental protein 5 (PP5) and matrix-associated serine proteinase inhibitor (MSPI), is a member of the TIMP family and represents a Kunitz-type proteinase inhibitor with homology to TFPI1 (5-7). In contrast to TFPI1, TFPI2 is a highly specific inhibitor of interstitial collagenases and gelatinases such as MMP2 and MMP9, but has very little 
effect on tissue factor itself (8). In primary gliomas, TFPI2 up-regulation correlates with a non-invasive phenotype, while low expression correlates with high-grade, and a highly invasive phenotype (9). Overexpression of TFPI2 in highgrade aggressive glioma cell lines reduces their invasive behaviour $(10,11)$.

In recent years, we have been seeking new mechanisms of neuroblastoma progression. We have shown that activin-A is negatively controlled by the $M Y C N$ oncogene and inhibits growth of experimental human neuroblastomas by reducing the angiogenic potential of the tumour and up-regulating the ECM molecule keratoepithelin (also known as Bigh3 =TGFßinduced h3) $(2,12)$. High expression of keratoepithelin in neuroblastoma is associated with a decrease in proliferation and invasion of neuroblastoma cells in vitro and a dramatic growth reduction of experimental neuroblastomas in vivo (13). In a global gene expression analysis we found TFPI2 most prominently up-regulated in keratoepithelin-transfected neuroblastoma cells. We therefore sought to determine the relationship between MYCN (as a marker for poor patient outcome), keratoepithelin and TFPI2 in more detail. We here show that expression of keratoepithelin and TFPI 2 correlates negatively with high $M Y C N$ expression (resulting from gene amplification) in primary human neuroblastoma and in neuroblastoma cell lines and that TFPI2 expression in neuroblastoma correlates positively with keratoepithelin expression. Additionally we show that keratoepithelin expression induces elevated TFPI 2 transcript levels despite high MYCN expression and suggest that TFPI 2 may be a novel prognostic marker in neuroblastoma.

\section{Materials and methods}

If not stated otherwise, all chemicals were purchased from Sigma (Taufkirchen, Germany), Fluka (Buchs, Switzerland), Merck (Schwalbach, Germany) or local suppliers.

Cell culture. All neuroblastoma cells were cultured in RPMI1640 medium (Cambrex, Verviers, Belgium) containing 1\% penicillin/streptomycin and 10\% foetal calf serum (Biochrom, Berlin, Germany). Cells transfected with vectors were continuously selected with G418 $(100 \mu \mathrm{g} / \mathrm{ml})$ (Invitrogen, Carlsbad, CA) in the above medium. The following cell lines were investigated: CHLA 20, CHLA 90, CHP 100*, CHP 134*, Gi-men, IMR $32^{*}$, IMR $^{*}, \mathrm{KCN}, \mathrm{Kelly}{ }^{*}$, Lan $1^{*}$, Lan $2^{*}$, Lan $5^{*}$, Lan 6*, NB 69, NB-LS, NGP*, NLF* ${ }^{*}$, NMB $^{*}$, Sh-ep, Sh-in, Sh-SY5Y, SK-N-AS, SK-N-SH, SMS-Kan* ("cell lines with $M Y C N$ amplification).

Cloning of keratoepithelin cDNA and transfection of cells. Neuroblastoma cell line Kelly was transfected with a vector containing keratoepithelin cDNA as previously reported (13).

RNA isolation. Cells were rinsed once with phosphate-buffered saline (PBS) and harvested with Trizol (Invitrogen, Carlsbad, CA) directly from the culture plate. Further RNA isolation was performed according to the manufacturer's protocol.

$c D N A$ production. For the production of cDNA we used $2 \mu \mathrm{g}$ total RNA per reaction together with Omniscript reverse transcriptase (Qiagen, Hilden, Germany) according to the manufacturer's recommendations. Primers used were random hexamers (Invitrogen, Carlsbad, CA).

Real-time RT-PCR. Real-time RT-PCR was performed as described recently (13). Primers were as follows: KE fwd 5'tttatcgtaatagcctctgcattga-3', KE rev 5'-catgacagtcccattgggg-3'; TFPI2 fwd 5'-cgatgcttgctggaggataga-3', TFPI2 rev 5'-acactgg tcgtccacactcact-3'; and B-Actin fwd 5'-gcatcccccaaagttcacaa-3', ß-Actin rev 5'-aggactgggccattctcct-3'.

Multiplex RT-PCR. Multiplex RT-PCR was used to determine $M Y C N$ transcript abundance in neuroblastoma cell lines. Per reaction $(50 \mu 1)$ we used the following material: $5 \mu 110 \mathrm{X}$ buffer (Genecraft, Lüdinghausen, Germany), $5 \mu 1$ dNTP ( 2 mM each), 5 pmol MYCN fwd, 5 pmol MYCN rev, 10 pmol Actin fwd, 10 pmol Actin rev, $0.2 \mu 1$ (1U) Taq polymerase (Genecraft, Lüdinghausen, Germany), $5 \mu \mathrm{l}$ cDNA (equivalent to $0.1 \mu \mathrm{g}$ total RNA), and Aqua ad. $50 \mu 1$. Primers were as follows: MYCN fwd cetgagcgattcagatgatga-3', MYCN rev 5'-cactgtcc tccgagtcagagtt-3'; and Actin fwd 5'-tgaagatcaagatcattgctcc-3', Actin rev 5'-cacgaaagcaatgctatcacc-3'.

Microarray experiments. Expression profiles of keratoepithelinoverexpressing cells (KB 24) and vector control cells (Kelly vec) were obtained on G4112A whole human genome microarrays (Agilent Technologies, Palo Alto, CA). RNA for this experiment was prepared with the RNeasy kit (Qiagen) as recommended by the manufacturer. Processing of the RNA and labelling was performed according to protocols by Agilent. Each cRNA probe was labelled with $\mathrm{Cy} 3$ and $\mathrm{Cy} 5$ and hybridized crosswise in a dye-swap fashion to avoid artefacts due to dye irregularities. Each dye combination was hybridized to arrays in 3 replicates; therefore 6 arrays were used for final statistics. The normalization of the raw microarray data was performed with a non-linear loess regression (14) and differentially expressed genes were identified by an ANOVAprocedure (15). The resulting p-values from the test statistics for significance were adjusted with the Benjamini-Hochberg method to control the false discovery rate (16).

Primary tumour samples of 68 neuroblastoma patients (stage $1, n=20$; stage $2, n=16$; stage $3, n=7$; stage $4, n=15$; and stage $4 s, n=10$ ) were analyzed for keratoepithelin expression using Affymetrix U95A microarrays as described previously $(17,18)$.

\section{Results}

Keratoepithelin and TFPI2 expression correlates negatively with MYCN amplification. We have recently reported that expression of keratoepithelin in neuroblastoma cell lines causes a change towards a benign phenotype, manifested by the loss of invasive properties and a dramatic decrease in tumour formation in vivo (13). We therefore sought to determine the molecular network behind this observation.

First, we investigated primary neuroblastoma samples of 68 patients using Affymetrix microarrays. However, we did not detect a correlation between keratoepithelin expression and clinical stages, patient outcome, survival or relapse. Nevertheless, we found an inverse correlation $(\mathrm{p}<0.05)$ 
a)

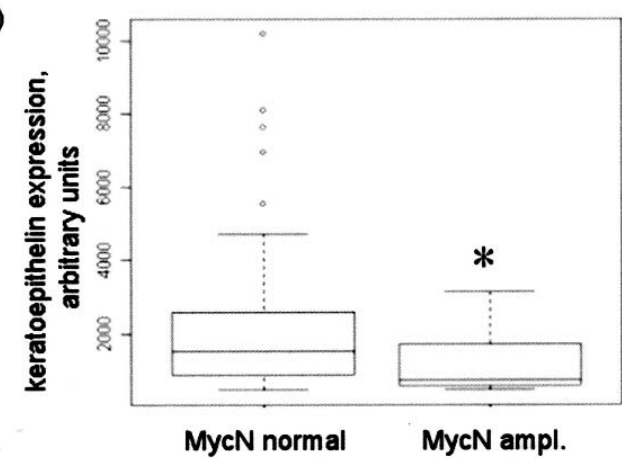

b)

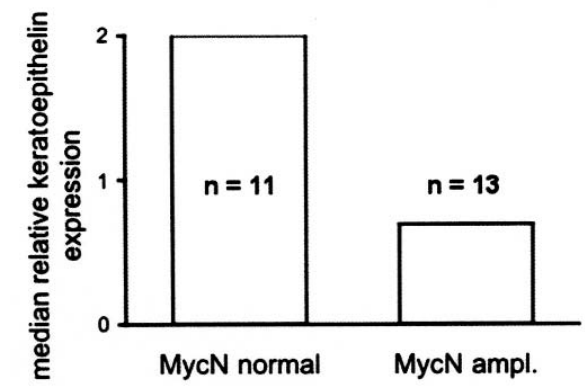

c)

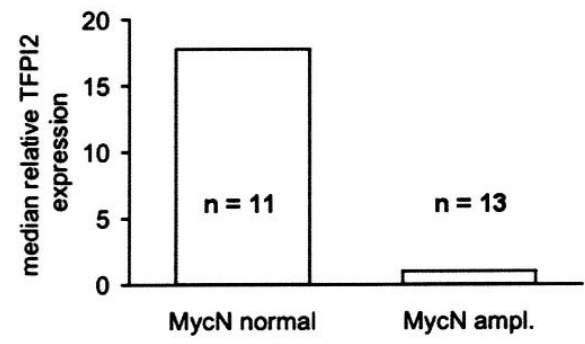

Figure 1. Expression of keratoepithelin and TFPI2 with respect to $M Y C N$ status. (a) Expression of keratoepithelin in tumour samples of 68 neuroblastoma patients was analyzed by Affymetrix microarrays. Means of keratoepithelin expression levels for patients with or without $M Y C N$ amplification are given with the quartile in a box and whiskers plot. Differences in keratoepithelin expression between the two groups were significant $(\mathrm{p}<0.05)$. (b) Keratoepithelin expression of 24 neuroblastoma cell lines was analyzed by real-time RT-PCR. Median relative expression of keratoepithelin mRNA is shown for cell lines with $M Y C N$ normoploidy $(\mathrm{n}=11)$ and cell lines bearing $M Y C N$ amplification $(n=13)$. Note that keratoepithelin expression is significantly higher in cell lines with normal MYCN expression. (c) Median relative TFPI2 expression determined by real-time RT-PCR in the same cell lines as in b. Note significantly higher expression of TFPI2 in cell lines with normal $M Y C N$ and high keratoepithelin expression.

between keratoepithelin expression and $M Y C N$ amplification (Fig. 1a).

Considering these results, we performed an expression analysis of 24 established and well-characterized neuroblastoma cell lines using multiplex and real-time RT-PCR. Again, we observed down-regulation of keratoepithelin transcripts in $M Y C N$-amplified cell lines compared to those with normal $M Y C N$. The median expression difference between the two groups was approximately 2-fold (Fig. 1b). As tissue factor pathway inhibitor (TFPI2) is predominantly up-regulated in keratoepithelin-transfected neuroblastoma cells (13), we studied the correlation between TFPI 2 expression and MYCN amplification. We performed real-time RT-PCR analyses on the same set of neuroblastoma cell lines and observed a pronounced inverse correlation (Fig. 1c). The median expression of TFPI 2 was approximately 20 -fold increased in cell

a)

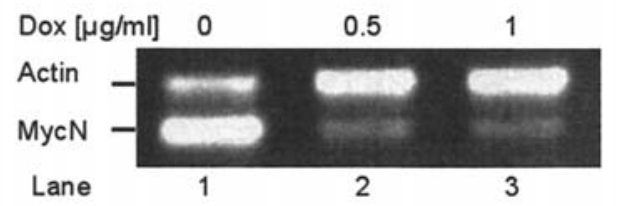

b)
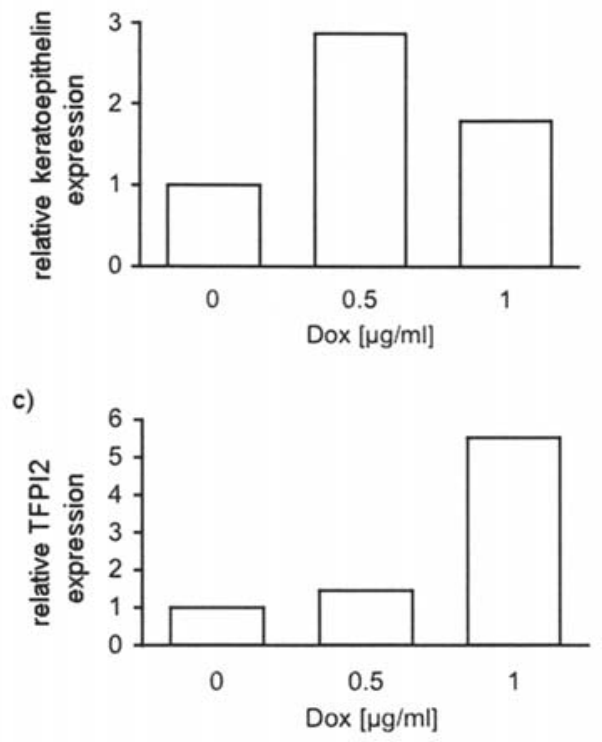

Figure 2. Down-regulation of MYCN in Tet2/N cells increases keratoepithelin and TFPI2 expression. (a) Visualisation of RT-PCR products for $\beta$-actin and MYCN demonstrating the diminished $M Y C N$ expression as a response to doxycycline (Dox) administration. Dox was applied for 2 days at indicated concentrations. (b and c) Keratoepithelin and TFPI2 expression, respectively, determined by real-time RT-PCR after 2 days of treatment with Dox. Values are given as ratios to untreated control cells. Note up-regulation of both keratoepithelin and TFPI 2 when $M Y C N$ is down-regulated.

lines with normal $M Y C N$ expression (not amplified; $\mathrm{n}=11$ ) as compared to those with $M Y C N$ amplification and high expression $(n=13)$.

Experimental regulation of keratoepithelin and TFPI2 by $M Y C N$. To study the relation between keratoepithelin, TFPI2 and MYCN in an experimental model, we chose the established cell line Tet2/N (19). This cell line, based on the neuroblastoma cell line Sh-ep, bears the MYCN oncogene under the control of a promoter that can be inactivated by a doxycycline (Dox)inducible repressor (Tet-off system). The inhibitory effect of Dox on MYCN expression in Tet2/N cells is shown in Fig. 2a. Using real-time RT-PCR analysis, we detected a three-fold and two-fold increase of keratoepithelin transcripts in Tet2/N cells treated with $0.5 \mu \mathrm{g} / \mathrm{ml}$ Dox and $1 \mu \mathrm{g} / \mathrm{ml}$ Dox, respectively, as compared to the untreated $(0 \mu \mathrm{g} / \mathrm{ml}$ Dox) cells (Fig. 2b). For TFPI2 we obtained a more pronounced dosage-dependent effect. Treatment with $0.5 \mu \mathrm{g} / \mathrm{ml}$ Dox caused a 1.5 -fold increase of TFPI 2 transcripts whereas $1 \mu \mathrm{g} / \mathrm{ml}$ Dox induced a 6-fold higher abundance of TFPI2 mRNA (Fig. 2c). In summary, both keratoepithelin and TFPI 2 mRNA levels increased when $M Y C N$ expression was reduced.

TFPI2 levels correlate positively with keratoepithelin expression in neuroblastoma cell lines. To further elucidate 
a)

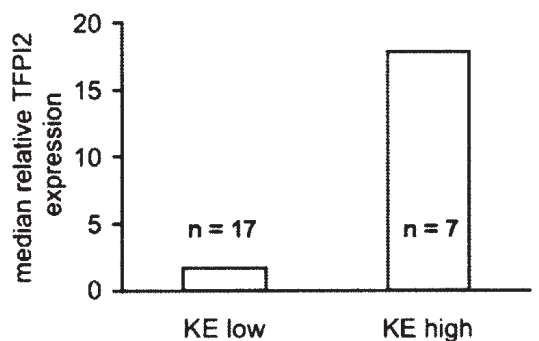

b)

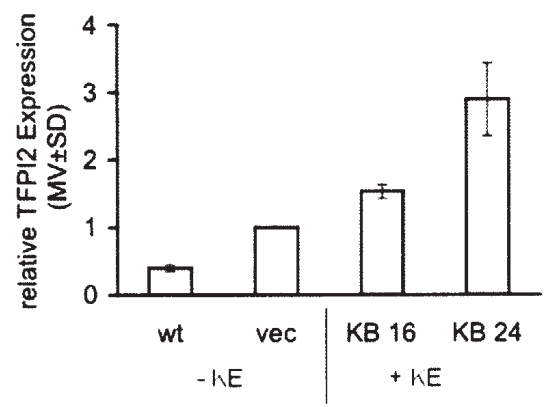

Figure 3. TFPI2 expression is up-regulated in keratoepithelin-expressing cells independent of the MYCN status. (a) Real-time RT-PCR analysis of TFPI2 expression in neuroblastoma cell lines with high and low keratoepithelin (KE) expression (KE high, $\mathrm{n}=7$; KE low, $\mathrm{n}=17$ ). Median expression levels are given as ratios to the expression of TFPI 2 in the Kelly cell line, which was set to 1. (b) TFPI2 expression in neuroblastoma cell line Kelly without (wt, vec) and with (KB 16, KB 24) stable transfection of keratoepithelin cDNA. Relative expression levels are given \pm SD [wt, wild-type Kelly cells; vec, vector control; KB 16 and KB 24, independent single cell clones bearing moderate (KB 16) and high (KB 24) keratoepithelin expression].

the interdependence between TFPI 2 and keratoepithelin, we studied TFPI 2 transcript levels in 24 well-established neuroblastoma cell lines with low $(n=17)$ and high $(n=7)$ expression levels of keratoepithelin (as a reference cell line we used Kelly, which was the cell line used for transfection experiments). We found the median TFPI2 expression to be approximately 10-times higher in cell lines with high keratoepithelin mRNA abundance (Fig. 3a).

Keratoepithelin up-regulates TFPI2 independently of MYCN levels. To further elucidate the interactions of MYCN, TFPI2 and keratoepithelin, we performed real-time RT-PCR analyses of MYCN-amplified Kelly neuroblastoma cells stably transfected with keratoepithelin cDNA (Fig. 3b). Two clonal transfectants with moderate (KB16) and high (KB24) keratoepithelin expression were chosen and compared to vectortransfected cells (vec) and wild-type (wt) Kelly cells. TFPI2 expression increased with the amount of keratoepithelin expression of the cells. KB24 cells exhibited an approximately 6-fold and 3-fold increase in TFPI2 compared to wt and vec cells, respectively. The moderately keratoepithelin-expressing cell line KB16 only exhibited a moderate increase in TFPI2 (Fig. 3b). The results confirm a dose-dependent up-regulation of TFPI 2 by keratoepithelin by a cell line, which bears approximately 100 copies of $M Y C N$.

To the best of our knowledge this is the first evidence that i) MYCN down-regulates keratoepithelin levels in neuroblastoma, ii) keratoepithelin has a positive effect on TFPI2 expression and iii) MYCN is a negative regulator of TFPI2, presumably via its negative effects on keratoepithelin.

\section{Discussion}

The overexpression of MYCN, mainly caused by amplification of the gene, is of great prognostic value for the patients as these tumours are usually fast growing and aggressive $(1,3)$. The physiological role of MYCN in neuronal development is to accelerate the growth of precursor cell populations and retain them in an undifferentiated state $(20,21)$. As neuroblastoma is derived from sympathetic embryonic neuroblasts this function holds also true for the tumour cells. High proliferative and migratory activity is of great importance during early-stage embryogenesis when sympathicoblasts migrate as neural crest cells into distant areas of the embryo. However, when the cells have reached their final destination, differentiation takes place, which may be controlled by local cues. Finally, only those sympathicoblasts survive, which have obviously established functional networks. A massive decrease of the size of sympathetic paraganglia then takes place, which can be observed in children of 18 months of age. The mechanisms that regulate development and differentiation of sympathicoblasts are not fully understood, as neither is the great heterogeneity of neuroblastoma behaviour and progression.

MYCN and keratoepithelin are inversely regulated in neuroblastoma. We have recently shown that expression of keratoepithelin in neuroblastoma cell lines with $M Y C N$ amplification leads to a decrease in proliferation and invasion, and inhibition of tumour growth in nude mice (13). Keratoepithelin is an extra-cellular matrix (ECM) constituent that forms fibrillar structures and interacts with type-I collagen, laminin, fibronectin and integrins (22-26). Keratoepithelin can change tumour behaviour to a more benign phenotype whereas amplification of $M Y C N$ is the most unfavourable marker in neuroblastoma. We therefore tried to elucidate the interdependence of keratoepithelin and MYCN.

We used samples from 68 neuroblastoma patients and compared their expression profiles on Affymetrix microarrays. Although we could not find a significant correlation between keratoepithelin expression and clinical stages, patient outcome, survival or relapse, we were able to demonstrate a significant negative correlation $(\mathrm{p}<0.05)$ with the amplification status of the MYCN oncogene. We sought to verify this result by investigating neuroblastoma cell lines. In 24 neuroblastoma cell lines studied by real-time RT-PCR we have found that the median expression level of keratoepithelin is approximately two-fold higher when the $M Y C N$ gene shows a normal diploid state, as compared to cell lines with $M Y C N$ amplification. Besides these correlative data, our study shows the regulatory effects of MYCN on keratoepithelin in an experimental model of in vitro $\mathrm{MYCN}$ down-regulation, using Tet $2 / \mathrm{N}$ cells, which express $M Y C N$ under the control of a tetracycline-repressible promoter. These cells are derived from the neuroblastoma cell line Sh-ep, which expresses keratoepithelin under normal culture conditions. These experiments confirm the initial findings of our microarray data and suggest that keratoepithelin is a target of MYCN. We show that the two molecules, which have opposing effects on cell proliferation and differentiation, are inversely regulated. The fact that keratoepithelin expression does not show a positive correlation with patient outcome, survival or relapse may be difficult to explain since we have 


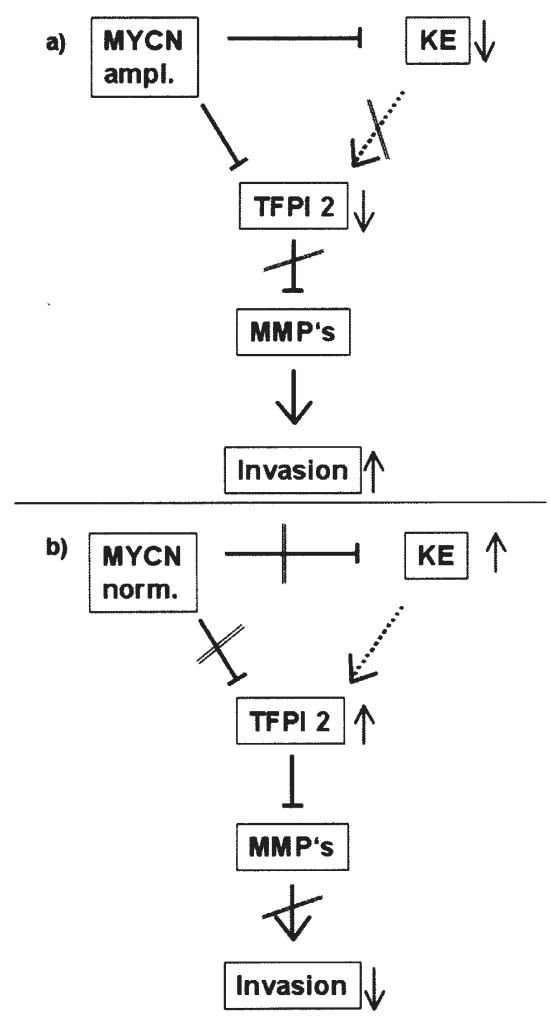

Figure 4. Proposed model of the interdependence of MYCN, keratoepithelin (KE) and TFPI2. (a) When MYCN expression is high, KE and TFPI2 expression are blocked. Also, low KE expression cannot activate TFPI2 expression, promoting MMP-dependent degradation of the extra-cellular matrix. (b) When MYCN is down-regulated, expression of KE and TFPI2 increase. Additionally, high KE expression induces TFPI2 expression independently of the MYCN status. TFPI2 is secreted into the extra-cellular matrix and inhibits MMPs, which reduces the invasiveness of tumour cells.

previously shown that its expression reduces the malignancy of neuroblastoma cell lines dramatically (13). However, a likely explanation is that neuroblastomas with high levels of keratoepithelin are not aggressive and belong to those that differentiate, regress and never become clinically evident. Conflicting results have been reported by Alaminos and colleagues (27). Solely based on microarray data, they have previously reported that keratoepithelin (referred to as Tgfbi) is up-regulated in neuroblastomas with high MYCN expression. We do not agree with these findings.

MYCN and TFPI2 are inversely regulated in neuroblastoma. Tumour progression depends on the capability of tumour cells to invade adjacent healthy tissue and form local or distant metastases. Invasiveness of tumour cells is increased by both up-regulation of MMPs and down-regulation of proteinase inhibitors (28). In neuroblastoma an increased invasive potential has been associated with the expression of MMP2 (29). MMP2 is a collagenase with high specificity for type-IV and type-I collagen. Its activity is fine tuned by both activators and inhibitors (30). TFPI2 is a strong inhibitor of MMPs, specifically MMP2 and MMP9. Recent studies have suggested that down-regulation of TFPI2 may be a prognostic marker, as hypermethylation of TFPI2 was reported to occur more frequently in choriocarcinomas, gliomas and cervix carcinoma than in healthy tissue $(11,31,32)$.
We have found that high TFPI2 expression correlates positively with MYCN normoploidy in a set of 24 human neuroblastoma cell lines. Therefore, TFPI2 is not only downregulated in tumour tissues as outlined above, but at least in neuroblastoma, a high TFPI2 expression also correlates with good-prognosis tumours. Thereby TFPI2 may be under direct control of MYCN. Our data provide evidence for the existence of a direct link between MYCN and TFPI2. This has been shown in the Tet2/N model system, which allows downregulation of $M Y C N$ by Dox. Administration of Dox reduces the level of $M Y C N$ transcripts, while TFPI2 expression increases.

Keratoepithelin up-regulates TFPI2 in neuroblastoma. Since both keratoepithelin and TFPI 2 were regulated by MYCN in our experiments, we sought to determine if there is a direct interaction between the two molecules. We compared TFPI2 transcript abundance in keratoepithelin-expressing and nonexpressing human neuroblastoma cell lines and found a significant positive correlation between both molecules. In a second approach, we studied the keratoepithelin-transfected cell lines KB16 and KB24 and compared them to the parental cell line Kelly and vector controls, all harbouring approximately 100 copies of MYCN. In summary, our data show that TFPI 2 mRNA levels increase upon keratoepithelin expression, providing evidence for an MYCN-independent regulation of TFPI2 by keratoepithelin. Therefore, TFPI2 as a central regulator of tumour cell invasiveness is regulated at least two-fold, negatively by MYCN expression and positively by keratoepithelin expression. The data are schematically summarized in Fig. 4.

Taken together, we provide the first evidence that i) keratoepithelin expression correlates negatively with $M Y C N$ amplification and expression in primary human neuroblastomas and in neuroblastoma cell lines; ii) TFPI2 expression in neuroblastoma also correlates negatively with $M Y C N$ expression, but positively with keratoepithelin expression, and iii) keratoepithelin induces elevated TFPI2 transcript levels in cells without alteration of $M Y C N$ expression and independent of $M Y C N$ amplification. TFPI2, like keratoepithelin, is a constituent of the ECM, which shows that the aggressiveness of MYCN-overexpressing neuroblastoma may not only be a result of increased proliferation and higher consumption of nutrients, but rather due to the changes in the tumour cell environment. We suggest that keratoepithelin can contribute to a less invasive phenotype in neuroblastoma by up-regulating TFPI2, which has a direct inhibitory effect on MMPs. The down-regulation of both keratoepithelin and TFPI 2 by MYCN, which correlates with a fast growing, aggressive tumour behaviour, supports this conclusion. Even though these experiments allow a deeper insight into the complex behaviour of neuroblastoma, both keratoepithelin and TFPI 2 call for further investigation, as they seem to have the potential to improve stratification and treatment. Still, the mechanism of keratoepithelin-induced up-regulation of TFPI 2 needs to be addressed.

\section{Acknowledgements}

We thank Mrs. Melanie Böning, Mrs. Monika Hoch and Mr. Marco Winkler for their excellent technical assistance. 
JB is funded by a grant of the Wilhelm-Sander-Stiftung. SV is funded by the Graduiertenkolleg 1034 der Deutschen Forschungsgemeinschaft.

\section{References}

1. Brodeur GM: Neuroblastoma: biological insights into a clinical enigma. Nat Rev Cancer 3: 203-216, 2003.

2. Schramm A, von Schuetz V, Christiansen $\mathrm{H}$, et al: High activin A-expression in human neuroblastoma: suppression of malignant potential and correlation with favourable clinical outcome. Oncogene 24: 680-687, 2005.

3. Westermann F and Schwab M: Genetic parameters of neuroblastomas. Cancer Lett 184: 127-147, 2002.

4. Baker AH, Edwards DR and Murphy G: Metalloproteinase inhibitors: biological actions and therapeutic opportunities. J Cell Sci 115: 3719-3727, 2002.

5. Miyagi Y, Koshikawa N, Yasumitsu H, et al: cDNA cloning and mRNA expression of a serine proteinase inhibitor secreted by cancer cells: identification as placental protein 5 and tissue factor pathway inhibitor-2. J Biochem 116: 939-942, 1994.

6. Rao CN, Reddy P, Liu Y, et al: Extracellular matrix-associated

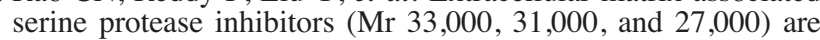
single-gene products with differential glycosylation: cDNA cloning of the $33-\mathrm{kDa}$ inhibitor reveals its identity to tissue factor pathway inhibitor-2. Arch Biochem Biophys 335: 82-92, 1996.

7. Sprecher CA, Kisiel W, Mathewes S and Foster DC: Molecular cloning, expression, and partial characterization of a second human tissue-factor-pathway inhibitor. Proc Natl Acad Sci USA 91: 3353-3357, 1994.

8. Herman MP, Sukhova GK, Kisiel W, et al: Tissue factor pathway inhibitor-2 is a novel inhibitor of matrix metalloproteinases with implications for atherosclerosis. J Clin Invest 107: 1117-1126, 2001.

9. Rao CN, Lakka SS, Kin Y, et al: Expression of tissue factor pathway inhibitor 2 inversely correlates during the progression of human gliomas. Clin Cancer Res 7: 570-576, 2001.

10. Konduri SD, Rao CN, Chandrasekar N, et al: A novel function of tissue factor pathway inhibitor-2 (TFPI-2) in human glioma invasion. Oncogene 20: 6938-6945, 2001.

11. Konduri SD, Yanamandra N, Dinh DH, et al: Physiological and chemical inducers of tissue factor pathway inhibitor-2 in human glioma cells. Int J Oncol 22: 1277-1283, 2003.

12. Skonier J, Neubauer M, Madisen L, Bennett K, Plowman GD and Purchio AF: cDNA cloning and sequence analysis of beta ig-h3, a novel gene induced in a human adenocarcinoma cell line after treatment with transforming growth factor-beta. DNA Cell Biol 11: 511-522, 1992.

13. Becker J, Erdlenbruch B, Noskova I, et al: Keratoepithelin suppresses the progression of experimental human neuroblastomas. Cancer Res 66: 5314-5321, 2006.

14. Yang YH, Dudoit S, Luu P, et al: Normalization for cDNA microarray data: a robust composite method addressing single and multiple slide systematic variation. Nucleic Acids Res 30: $\mathrm{e} 15,2002$.

15. Landgrebe J, Bretz F and Brunner E: Efficient design and analysis of two colour factorial microarray experiments. Comput Stat Data Anal 50: 499-517, 2006.
16. Bretz F, Landgrebe $\mathrm{J}$ and Brunner E: Multiplicity issues in microarray experiments. Methods Inf Med 44: 431-437, 2005.

17. Schramm A, Schulte JH, Klein-Hitpass L, et al: Prediction of clinical outcome and biological characterization of neuroblastoma by expression profiling. Oncogene 24: 7902-7912, 2005.

18. Schulte JH, Schramm A, Klein-Hitpass L, et al: Microarray analysis reveals differential gene expression patterns and regulation of single target genes contributing to the opposing phenotype of TrkA- and TrkB-expressing neuroblastomas. Oncogene 24: 165-177, 2005.

19. Lutz W, Stohr M, Schurmann J, Wenzel A, Lohr A and Schwab M: Conditional expression of N-myc in human neuroblastoma cells increases expression of alpha-prothymosin and ornithine decarboxylase and accelerates progression into S-phase early after mitogenic stimulation of quiescent cells. Oncogene 13: 803-812, 1996.

20. Sears RC and Nevins JR: Signaling networks that link cell proliferation and cell fate. J Biol Chem 277: 11617-11620, 2002.

21. Yaari S, Jacob-Hirsch J, Amariglio N, Haklai R, Rechavi G and Kloog Y: Disruption of cooperation between Ras and $\mathrm{MycN}$ in human neuroblastoma cells promotes growth arrest. Clin Cancer Res 11: 4321-4330, 2005

22. Kim JE, Kim SJ, Lee BH, Park RW, Kim KS and Kim IS: Identification of motifs for cell adhesion within the repeated domains of transforming growth factor-beta-induced gene, betaig-h3. J Biol Chem 275: 30907-30915, 2000.

23. Kim JE, Jeong HW, Nam JO, et al: Identification of motifs in the fasciclin domains of the transforming growth factor-betainduced matrix protein betaig-h3 that interact with the alphavbeta5 integrin. J Biol Chem 277: 46159-46165, 2002.

24. Nam JO, Kim JE, Jeong HW, et al: Identification of the alphavbeta 3 integrin-interacting motif of betaig-h3 and its antiangiogenic effect. J Biol Chem 278: 25902-25909, 2003.

25. Hashimoto K, Noshiro M, Ohno S, et al: Characterization of a cartilage-derived 66-kDa protein (RGD-CAP/beta ig-h3) that binds to collagen. Biochim Biophys Acta 1355: 303-314, 1997.

26. Hanssen E, Reinboth B and Gibson MA: Covalent and noncovalent interactions of betaig-h3 with collagen VI. Beta ig-h3 is covalently attached to the amino-terminal region of collagen VI in tissue microfibrils. J Biol Chem 278: 24334-24341, 2003.

27. Alaminos M, Mora J, Cheung NK, et al: Genome-wide analysis of gene expression associated with MYCN in human neuroblastoma. Cancer Res 63: 4538-4546, 2003.

28. Deryugina EI and Quigley JP: Matrix metalloproteinases and tumor metastasis. Cancer Metastasis Rev 25: 9-34, 2006.

29. Hecht M, Papoutsi M, Tran HD, Wilting J and Schweigerer L: Hepatocyte growth factor/c-Met signaling promotes the progression of experimental human neuroblastomas. Cancer Res 64: 6109-6118, 2004

30. Nagase H, Suzuki K, Morodomi T, Enghild JJ and Salvesen G: Activation mechanisms of the precursors of matrix metalloproteinases 1, 2 and 3. Matrix (Suppl) 1: 237-244, 1992.

31. Hube F, Reverdiau P, Iochmann S, Cherpi-Antar C and Gruel Y: Characterization and functional analysis of TFPI-2 gene promoter in a human choriocarcinoma cell line. Thromb Res 109: 207-215, 2003.

32. Sova P, Feng Q, Geiss G, et al: Discovery of novel methylation biomarkers in cervical carcinoma by global demethylation and microarray analysis. Cancer Epidemiol Biomarkers Prev 15: 114-123, 2006. 